BMC

Microbiology

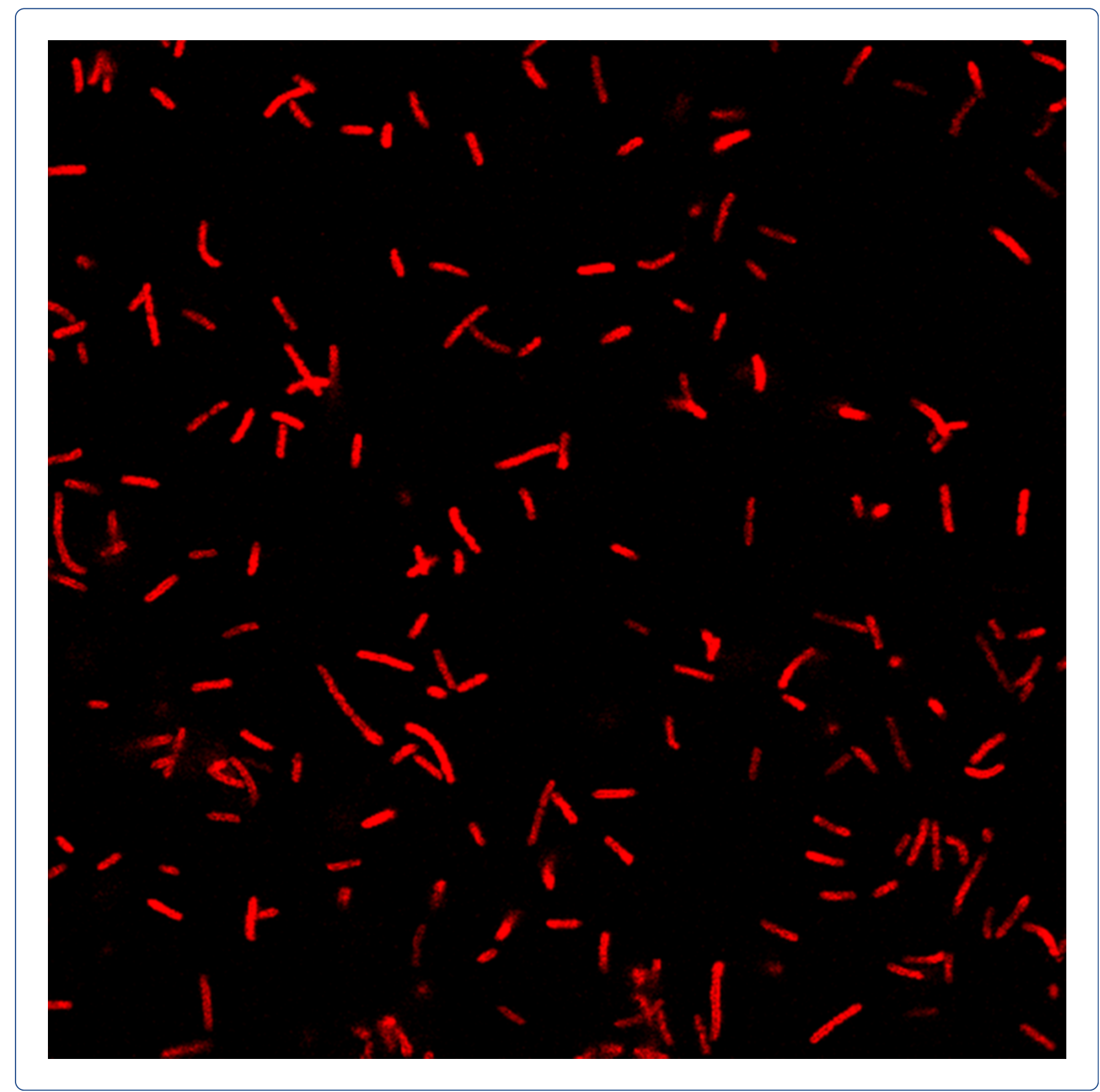

Mechanistic studies of intracellular delivery of proteins by cell-penetrating peptides in cyanobacteria

Liu et al. 


\title{
Mechanistic studies of intracellular delivery of proteins by cell-penetrating peptides in cyanobacteria
}

\author{
Betty R Liu', Yue-Wern Huang ${ }^{2}$ and Han-Jung Lee 1* $^{\text {* }}$
}

\begin{abstract}
Background: The plasma membrane plays an essential role in selective permeability, compartmentalization, osmotic balance, and cellular uptake. The characteristics and functions of cyanobacterial membranes have been extensively investigated in recent years. Cell-penetrating peptides (CPPs) are special nanocarriers that can overcome the plasma membrane barrier and enter cells directly, either alone or with associated cargoes. However, the cellular entry mechanisms of CPPs in cyanobacteria have not been studied.
\end{abstract}

Results: In the present study, we determine CPP-mediated transduction efficiency and internalization mechanisms in cyanobacteria using a combination of biological and biophysical methods. We demonstrate that both Synechocystis sp. PCC 6803 and Synechococcus elongatus PCC 7942 strains of cyanobacteria possess red autofluorescence. Green fluorescent protein (GFP), either alone or noncovalently associated with a CPP comprised of nine arginine residues (R9/GFP complexes), entered cyanobacteria. The ATP-depleting inhibitor of classical endocytosis, N-ethylmaleimide (NEM), could block the spontaneous internalization of GFP, but not the transduction of R9/GFP complexes. Three specific inhibitors of macropinocytosis, cytochalasin D (CytD), 5-(N-ethyl-N-isopropyl)amiloride (EIPA), and wortmannin, reduced the efficiency of R9/GFP complex transduction, indicating that entry of R9/GFP complexes involves macropinocytosis. Both the 1-(4,5-dimethylthiazol-2-yl)-3,5-diphenylformazan (MTT) and membrane leakage analyses confirmed that R9/GFP complexes were not toxic to the cyanobacteria, nor were the endocytic and macropinocytic inhibitors used in these studies.

Conclusions: In summary, we have demonstrated that cyanobacteria use classical endocytosis and macropinocytosis to internalize exogenous GFP and CPP/GFP proteins, respectively. Moreover, the CPP-mediated delivery system is not toxic to cyanobacteria, and can be used to investigate biological processes at the cellular level in this species. These results suggest that both endocytic and macropinocytic pathways can be used for efficient internalization of regular protein and CPP-mediated protein delivery in cyanobacteria, respectively.

Keywords: Cell-penetrating peptide (CPP), Endocytosis, Green fluorescent protein (GFP), Macropinocytosis, Protein transduction, Red fluorescent protein (RFP)

\section{Background}

Cyanobacteria, also known as blue-green algae, are photosynthetic prokaryotes. They played a key role in the evolution of life on Earth, converting the early reducing atmosphere into an oxidizing one as they performed oxygenic photosynthesis [1]. Cyanobacteria are thought to be progenitors of chloroplasts via

\footnotetext{
* Correspondence: hjlee@mail.ndhu.edu.tw

'Department of Natural Resources and Environmental Studies, National Dong Hwa University, Hualien 97401, Taiwan

Full list of author information is available at the end of the article
}

endosymbiosis [2]. Approximately, 20-30\% of Earth's photosynthetic activity is due to cyanobacteria. The proteomic composition and dynamics of plasma membranes of cyanobacteria have been extensively characterized $[2,3]$. However, the influence of the structure and composition of cyanobacterial membranes on cellular uptake remains largely unknown. Delivery of exogenous DNA into cyanobacteria was first reported in 1970 [4], although the internalization mechanisms are still unknown [1]. Since cyanobacteria play key roles in supporting life on Earth and have potential in biofuel 
production and other industrial applications [5-7], understanding how they interact with the environment by processes such as internalization of exogenous materials, is becoming increasingly important.

The plasma membrane provides a barrier that hinders the cellular entry of macromolecules, including DNAs, RNAs, and proteins. In 1988, two groups simultaneously identified a protein called transactivator of transcription (Tat) from the human immunodeficiency virus type 1 (HIV-1) that possesses the ability to traverse cellular membranes $[8,9]$. The penetrating functional domain of the Tat protein is comprised of 11 amino acids (YGRKKRRQRRR) [10]. Subsequently, many peptide analogues of the basic amino acid-rich domain of the Tat protein were synthesized and evaluated for membrane transduction potential $[11,12]$. These positively charged, amphipathic peptides were termed cell-penetrating peptides (CPPs) or protein transduction domains (PTDs) [11-13].

Among synthetic peptides, the cellular uptake of polyarginine was found to be much more efficient than that of polylysine, polyhistidine, or polyornithine [13,14]. We found that a nona-arginine (R9) CPP peptide can enter cells by itself or in conjunction with an associated cargo [15-21]. Cargoes that R9 can carry include proteins, DNAs, RNAs, and inorganic nanoparticles (notably, quantum dots; QDs). R9 can form complexes with cargoes in covalent, noncovalent, or mixed covalent and noncovalent manners [22-24]. CPPs can deliver cargoes up to $200 \mathrm{~nm}$ in diameter [11,25], and R9 can internalize into cells of various species, including mammalian cells/ tissues, plant cells, bacteria, protozoa, and arthropod cells $[16,17,26,27]$.

Despite many studies using various biological and biophysical techniques, our understanding of the mechanism of CPP entry remains incomplete and somewhat controversial. Studies have indicated that CPPs enter cells by energy-independent and energy-dependent pathways [28]. The concentration of CPPs appears to influence the mechanism of cellular uptake [28]. Our previous studies indicated that macropinocytosis is the major route for the entry of R9 carrying protein or DNA cargoes associated in a noncovalent fashion $[15,29,30]$. However, we found that CPP/QD complexes enter cells by multiple pathways [31,32]. Multiple pathways of cellular uptake were also demonstrated with CPP-fusion protein/cargo complexes associated in a mixed covalent and noncovalent manner [22,24]. In contrast, our study of the R9 modified with polyhistidine (HR9) indicated direct membrane translocation [33].

The cellular entry mechanisms of CPPs in cyanobacteria have not been studied. In the present study, we determined CPP-mediated transduction efficiency and internalization mechanisms in cyanobacteria using a combination of biological and biophysical methods.

\section{Results}

\section{Autofluorescence}

To detect autofluorescence in cyanobacteria, either live or methanol-killed cells were observed using a fluorescent microscope. Both 6803 and 7942 strains of cyanobacteria emitted red fluorescence under blue or green light stimulation (Figure 1, left panel) when alive; dead cells did not display any fluorescence (Figure 1, right panel). This phenomenon was confirmed using a confocal microscope; dead cyanobacteria treated with either methanol or killed by autoclaving emitted no red fluorescence (data not shown). Thus, red autofluorescence from cyanobacteria provided a unique character.

\section{Mechanistic studies of protein transduction}

To demonstrate protein transduction in cyanobacteria, both 6803 and 7942 strains were treated with either green fluorescent protein (GFP) alone or R9/GFP noncovalently complexed at a molecular ratio of 3:1. After $20 \mathrm{~min}$, the medium was removed, and cells were washed and observed using a confocal microscope. Surprisingly, green fluorescence was detected in both control and experimental groups in both strains (Figure 2a). Red autofluorescence indicated that the cells in both groups are alive (Figure 2a). To test whether GFP alone enters cyanobacteria by classical endocytosis, physical and pharmacological inhibitors, including low temperature, valinomycin, nigericin, $N$-ethylmaleimide (NEM), and sodium azide, were used. Endocytic efficiencies of GFP were significantly reduced in the 7942 strain treated with 1 and $2 \mathrm{mM}$ of NEM, while $2 \mathrm{mM}$ of NEM suppressed GFP uptake in the 6803 strain (Additional file 1: Figure S1A). All of these inhibitors reduced the entry of GFP, indicating that endocytosis is the route for spontaneous GFP internalization (Additional file 1: Figure S1B). Insofar as NEM was the most effective inhibitor of classical endocytosis in both stains (Additional file 1: Figure S1B), it was used in subsequent experiments.

To block classical energy-dependent endocytosis in cyanobacteria, NEM was added to cells for $1 \mathrm{~min}$ followed by addition of either GFP alone or R9/GFP complexes. We found that both strains treated with GFP emitted red fluorescence but not green fluorescence (Figure 2b). In contrast, both green and red fluorescence were detected in the cells treated with R9/GFP complexes (Figure 2b). Relative fluorescent intensities were analyzed and compared with control cells in the absence of NEM and R9. NEM treatment decreased green fluorescence in cells exposed to GFP alone (Figure 2c), but did not affect the level of green fluorescence in cells treated with R9/GFP mixtures (Figure 2c). These results suggest that GFP cannot cross NEM-treated cell membranes without the assistance of R9. Thus, we 


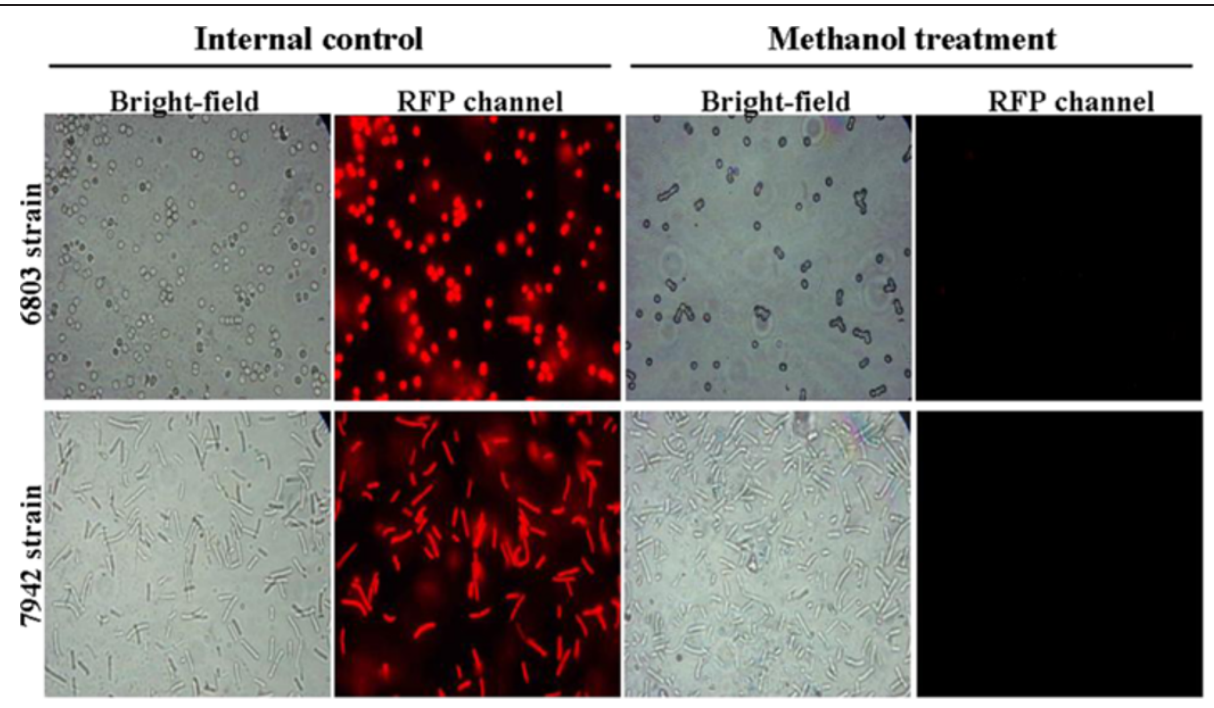

Figure 1 Autofluorescence detection in $\mathbf{6 8 0 3}$ and 7942 strains of cyanobacteria. Cells were treated with either BG-11 medium or 100\% methanol to cause cell death. Bright-field and fluorescent images in the RFP channel were used to determine cell morphology and autofluorescence, respectively. Images were recorded using an Eclipse E600 fluorescent microscope (Nikon) at a magnification of 1,000x.

hypothesize that there is an alternative route of protein transduction in cyanobacteria in addition to classical endocytosis.

To identify the alternative route for cellular entry of R9/ GFP complexes in cyanobacteria, we used macropinocytic inhibitors 5-( $N$-ethyl- $N$-isopropyl)-amiloride (EIPA), wortmannin, and cytochalasin D (CytD) in cells pretreated with NEM to block clathrin- and caveolin-dependent endocytosis. The cells were treated with either R9/GFP as a control or R9/GFP plus macropinocytic inhibitors. Significant reductions in the intensity of cellular green fluorescence were observed in treatments with CytD and wortmannin in the 6803 strain of cells, and with all of the macropinocytic inhibitors in the 7942 strain of cells (Figure 3). Wortmannin was the most effective inhibitor in the 6803 strain, while EIPA was the most effective inhibitor in the 7942 strain (Figure 3). These results indicate that protein transduction of R9 in cyanobacteria involves lipid raft-dependent macropinocytosis.

\section{Cytotoxicity}

To investigate whether treatments with R9 and GFP are toxic and cause membrane leakage, cytotoxicity was evaluated using cells treated with BG-11 medium and $100 \%$ methanol as negative and positive controls, respectively. In the presence of NEM, cells were incubated with R9/GFP complexes mixed with CytD, EIPA, or wortmannin as experimental groups, respectively. The 1(4,5-dimethylthiazol-2-yl)-3,5-diphenylformazan (MTT) assay was applied. There is a significant correlation $\left(\mathrm{R}^{2}\right.$ $=0.9949$ ) between cell number and activity of MTT reduction (Additional file 2: Figure S2A). Further, 100\% methanol, 100\% dimethyl sulfoxide (DMSO), and autoclave treatments were effective in causing cell death (Additional file 2: Figure S2B). We chose 100\% methanol treatment as a positive control for cytotoxicity analysis. The 6803 strain treated with R9/GFP complexes mixed with CytD, EIPA, or wortmannin in the presence of NEM was analyzed by the MTT assay. No cytotoxicity was detected in experimental groups, but significant reduction in cell viability was observed in the positive control (Figure 4A). To further confirm the effect of endocytic modulators on cell viability, the membrane leakage assay was conducted. No membrane damage was detected in the negative control and experimental groups (Figure 4B). These data indicate that R9/GFP and endocytic modulators were nontoxic to cyanobacteria.

\section{Discussion}

In this study, we demonstrate that both 6803 and 7942 strains of cyanobacteria use classical endocytosis for protein ingestion. Macropinocytosis is used by R9-mediated delivery system as an alternative route of cellular entry when classical endocytosis is blocked (Figure 2b, 2c, and 3). Our finding of macropinocytosis-mediated entry of a CPP is consistent with studies of protein and DNA delivery in other eukaryotic cells [29,30,34].

We also demonstrate that cyanobacteria possess red autofluorescence. Identification and quantification of cyanobacteria in environmental samples or cultures can be time-consuming (such as plating, fluorescent staining, and imaging) and sometimes costly. Schulze et al. recently presented a new and fast viability assay for the model organism 6803 strain of cyanobacteria [35]. This method used red autofluorescence of 6803 strain of cyanobacteria to differentiate viable cells from nonviable 
$\mathbf{a}$
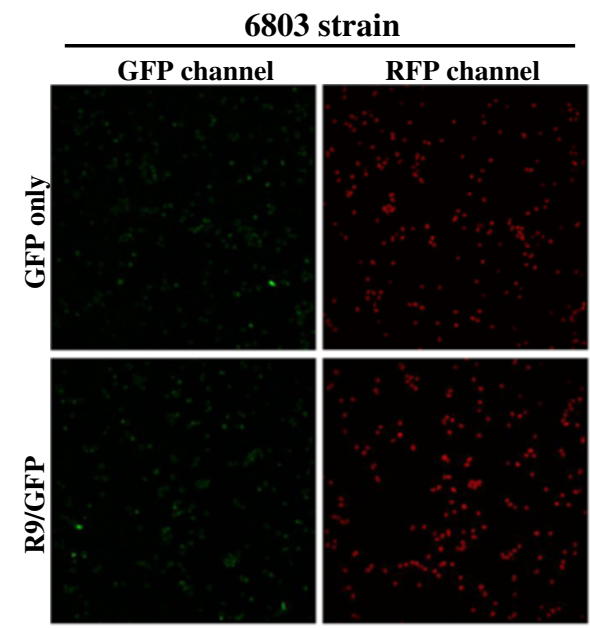

b
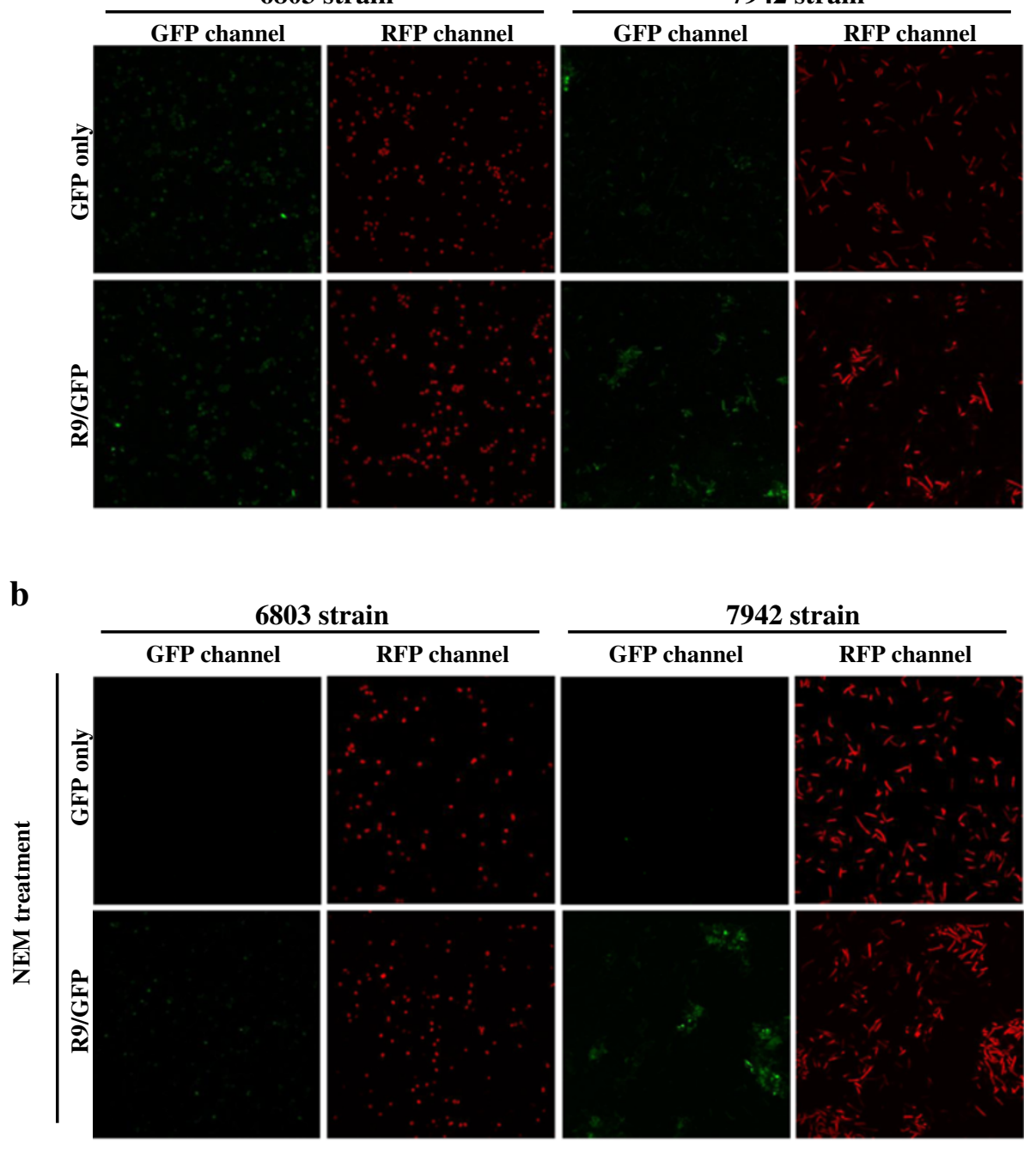

7942 strain

7942 strain

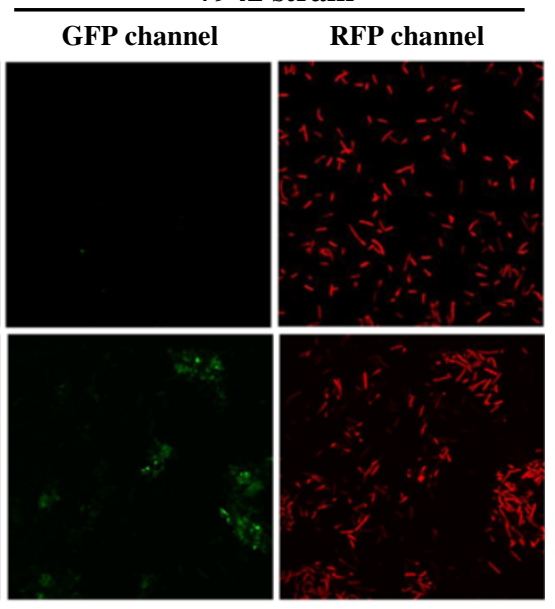

c
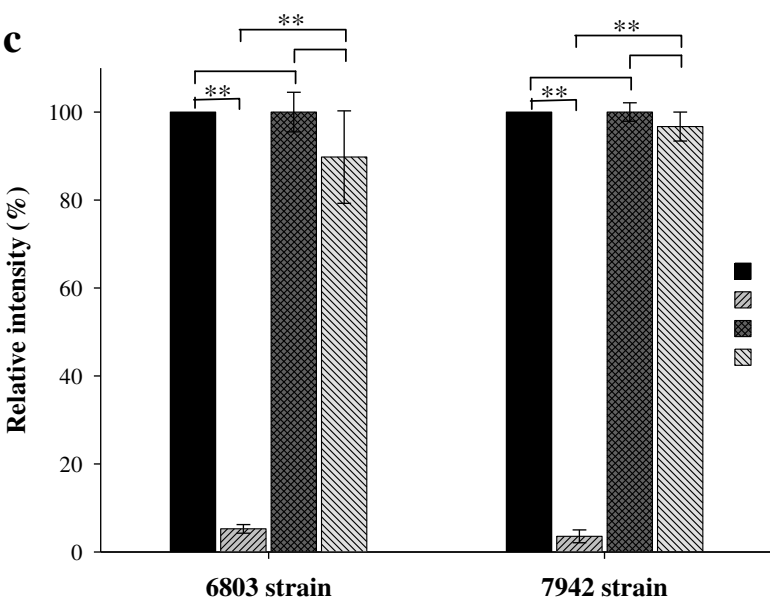

Figure $\mathbf{2}$ (See legend on next page.) 
(See figure on previous page.)

Figure 2 CPP-mediated GFP delivery in cyanobacteria. (a) The 6803 and 7942 strains of cyanobacteria were treated with GFP only or R9/GFP mixtures for 20 min at room temperature. (b) GFP delivery in the presence of the endocytic inhibitor NEM. Cells were pretreated with NEM, and then either GFP only or R9/GFP was added to cells for 20 min. Green and red fluorescence were detected in GFP and RFP channels using a Leica confocal microscope at a magnification of 1,000x (a and b). (c) Histogram of relative fluorescent intensity. Green fluorescence detected in the cells treated with only GFP served as a control. Fluorescent intensity detected in experimental groups was compared to that of the control group. Data are presented as mean \pm SD from three independent experiments. Significant differences were set at $P<0.05(*)$ or $0.01\left(^{* *}\right)$.

cells without tedious preparation [35-39]. A combination of this new assay with absorption spectra or chlorophyll concentration measurements was further proposed for more accurate quantification of the vitality of cyanobacteria [35].

Most previous reports have focused on photosynthesis as the major route by which cyanobacteria obtain nutrition, while only a handful of studies have evaluated endocytosis as a means of nutrition ingestion [1,40,41]. The first indication of macropinocytosis in cyanobacteria came from our initial screening of CPP-mediated noncovalent protein transduction among some representative organisms [26]. We found that the mechanism of protein transduction in cyanobacteria may involve both classical endocytosis and macropinocytosis [26]. While cyanobacteria contain cell walls and peptidoglycan layers [3], these structures did not hinder the penetration of CPPs in cyanobacteria (Figure 3), Gram-negative bacteria, Gram-positive bacteria and plants $[26,42,43]$. Our study is the first report that cyanobacteria use both endocytosis and macropinocytosis to internalize exogenous macromolecules (Figures 2 and 3). The sensitivity of cyanobacteria to macropinocytic inhibitors is strainspecific: the 6803 strain is more sensitive to wortmannin,

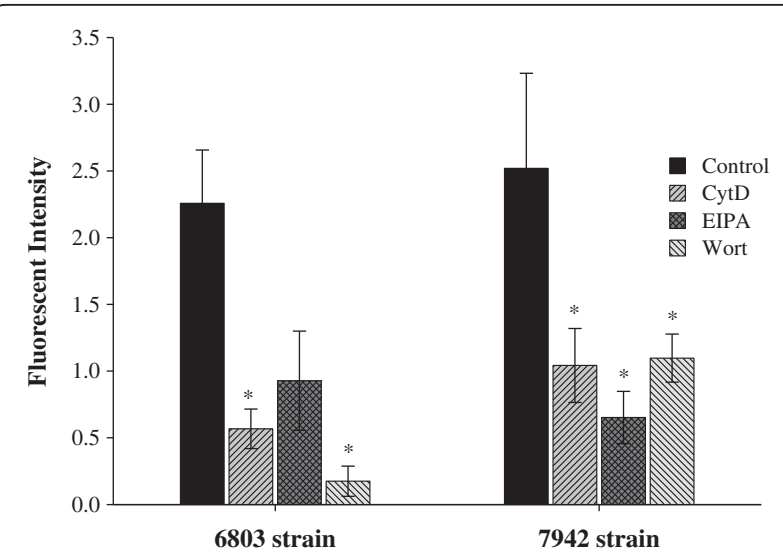

Figure 3 The mechanism of the CPP-mediated GFP delivery in 6803 and 7942 strains of cyanobacteria. Cells were treated with NEM and R9/GFP mixtures in the absence or presence of CytD, EIPA, or wortmannin (Wort), as indicated. Results were observed in the GFP channel using a confocal microscope, and fluorescent intensities were analyzed by the UN-SCAN-IT software. Data are presented as mean \pm SD from three independent experiments. Significant differences of $P<0.05\left(^{*}\right)$ are indicated. while EIPA is more highly effcetive at reducing protein transduction in the 7942 strain (Figure 3). There was no enough evidence yet to explain why NEM-treated cyanobacteria decreased green fluorescence in cells exposed to GFP alone. We hypothesize that the spontaneous internalization of GFP in cyanobacteria may be mediated heavily by energy-dependent endocytosis, which can be blocked by the ATP depletion reagent NEM (Figures 2 and 3). However, NEM could not completely inhibit CPPmediated macropinocytosis, which is lipid raft-dependent [25] and may be slightly energy-dependent [44].

Biofuels have emerged as one of promising sources for alternative energy. Initial biofuel development was based on the synthesis of ethanol using fermentative organisms and polysaccharides [1]. The limited availability of polysaccharides led to extensive research on the direct use of sunlight, the ultimate energy source on this planet. Photosynthetic microorganisms can accomplish this by fixing carbon dioxide and converting sunlight energy into chemical energy as fuel. This raises the possibility of using engineered cyanobacteria in two ways to improve phtotosynthetic biofuel production. Cyanobacteria could be either gene-engineered using recombinant DNA technology $[45,46]$ or protein-engineered using CPPmediated protein delivery method. Cyanobacteria have an advantage compared to eukaryotic algae in that the genetic manipulation of cyanobacteria is more straightforward and well-developed $[1,45]$. However, the protein engineering of cyanobacteria mediated by CPPs is just at its infancy.

\section{Conclusions}

In this study, we have demonstrated that both Synechocystis sp. PCC 6803 and Synechococcus elongatus PCC 7942 strains of cyanobacteria possess red autofluorescence. Cyanobacteria use classical endocytosis and macropinocytosis to internalize exogenous GFP and CPP/GFP proteins, respectively. Moreover, the CPPmediated delivery system is not toxic to cyanobacteria, and can be used to investigate biological processes at the cellular level in this species.

\section{Methods}

Culture of cyanobacteria

Synechocystis sp. PCC 6803 (American Type Culture Collection, Manassas, VA, USA, 27184) and Synechococcus 
A

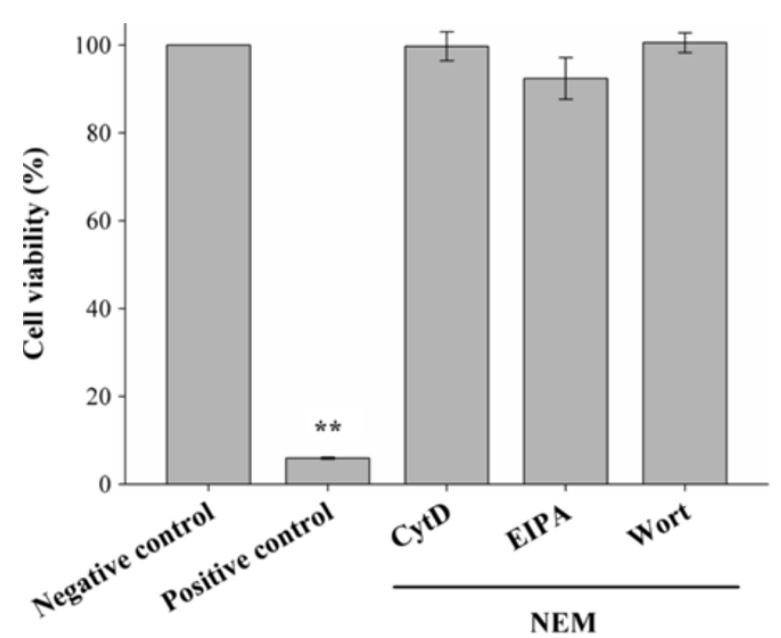

B

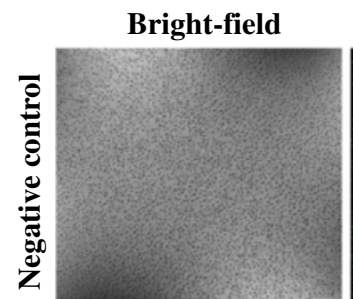

GFP channel

BFP channel
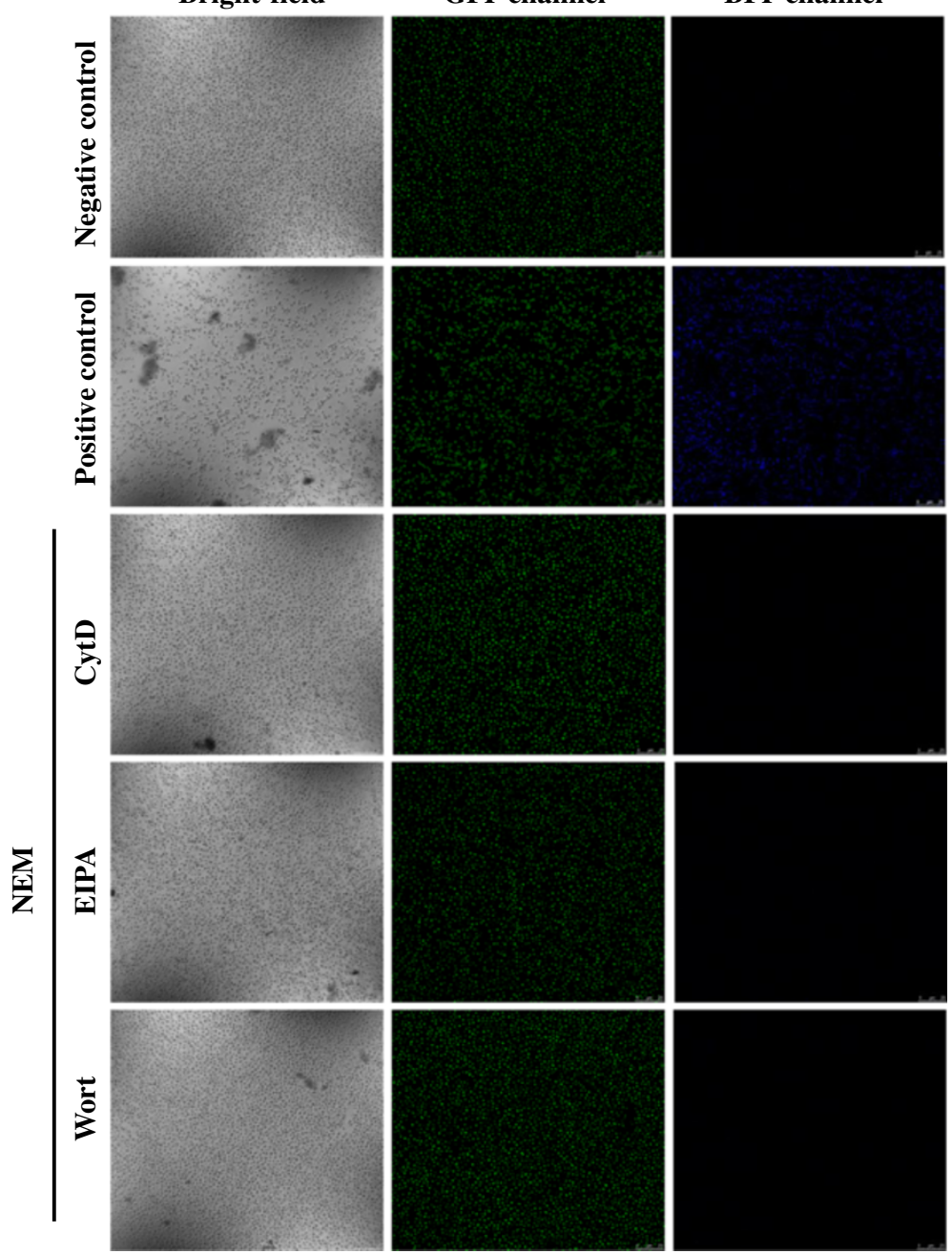

Figure 4 (See legend on next page.) 
(See figure on previous page.)

Figure 4 Cell viability of the R9/GFP delivery system in the presence of uptake modulators. (A) The MTT assay. The 6803 strain of cyanobacteria was treated with BG-11 medium as a negative control, or treated with 100\% methanol as a positive control. In the presence of NEM, cells were treated with R9/GFP complexes in the presence of CytD, EIPA, or wortmannin (Wort), respectively, and analyzed by the MTT assay. Significant differences were determined at $P<0.01\left(^{* *}\right)$. Data are presented as mean \pm SD from nine independent experiments. (B) The membrane leakage assay by a two-color fluorescence assay. The 6803 strain of cyanobacteria was treated with the same conditions in (A). SYTO 9 stains nucleic acids of live and dead cells in the GFP channel, while SYTOX blue stains nucleic acids of membrane-damaged cells in the BFP channel. Blue and green fluorescence were detected in BFP and GFP channels using a Leica confocal microscope at a magnification of 630x.

elongatus PCC 7942 (ATCC, 33912) were grown in BG-11 medium with mild shaking at $50 \mathrm{rpm}$ and regular illumination at $28^{\circ} \mathrm{C}$, as previously described [26].

\section{Plasmid construction and protein preparation}

We used a pR9 plasmid containing a hexa-histidine and an R9 sequence under the control of the T7 promoter, as previously described [42]. The pQE8-GFP plasmid consisted of the coding sequence of GFP under the control of the T5 promoter [42]. Plasmid DNA was purified using a Nucleobond AX100 Kit (Machery-Nagel, Duren, Germany).

Both pR9 and pQE8-GFP plasmids were transformed into Escherichia coli and induced, as previously described [47]. The expressed proteins were purified by one-step immobilized-metal chelating chromatography. The purified proteins were concentrated and dialyzed using the Amicon Ultra-4 centrifugal filter devices (Millipore, Billerica, MA, USA), as previously described [15]. Proteins were then quantified using a Protein Assay Kit (Bio-Rad, Hercules, CA, USA).

\section{Protein transduction and mechanism of cellular uptake}

The purified R9 peptide was mixed with GFP at a molecular ratio of 3:1 at room temperature for $10 \mathrm{~min}$. To investigate the delivery of exogenous proteins into cyanobacteria, cells were washed with double deionized water and treated with either GFP alone at a final concentration of $800 \mathrm{nM}$ or R9/GFP mixtures at a molecular ratio of 3:1. To determine the transduction of noncovalent protein complexes, 1 and $2 \mathrm{mM}$ of NEM (Sigma-Aldrich, St. Louis, MO, USA) was added to cyanobacteria, and either GFP alone or R9/GFP mixtures were then added to cyanobacteria for $20 \mathrm{~min}$ [26].

To evaluate the role of classical endocytosis, physical and pharmacological inhibitors, such as low temperature, $2 \mu \mathrm{M}$ of valinomycin [48], $2 \mu \mathrm{M}$ of nigericin [49], 1 and $2 \mathrm{mM}$ of $\mathrm{NEM}$ [50], $10 \mu \mathrm{M}$ of fusicoccin [51], and $10 \mathrm{mM}$ of sodium azide [49], were used, as previous described [31-33,52]. To study macropinocytosis, cells were treated with or without $100 \mu \mathrm{M}$ of EIPA (Sigma-Aldrich), $10 \mu \mathrm{M}$ of CytD (SigmaAldrich), or $100 \mathrm{nM}$ of wortmannin (Sigma-Aldrich) followed by the treatment of R9/GFP mixtures [31-33,52]. CytD is a blocker of the F-actin rearrangement that disrupts all forms of endocytosis, including clathrin-, caveolae-dependent endocytosis, and macropinocytosis $[31,33]$. EIPA is an inhibitor of the $\mathrm{Na}^{+} / \mathrm{H}^{+}$exchanger and specifically inhibits macropinocytosis $[31,53]$. Wortmannin interrupts the action of phosphoinositide 3-kinase, which plays the key role in macropinocytosis [53,54]. Protein transduction was quantified by fluorescent and confocal microscopy.

\section{Cytotoxicity assay}

Cyanobacteria were treated with either BG-11 medium or $100 \%$ methanol [55] for $24 \mathrm{~h}$ as a negative or positive control, respectively. The MTT assay was used to determine cell viability $[16,56]$. Cells were treated with $100 \%$ methanol, 100\% DMSO, autoclave, or R9/GFP complexes in the presence of endocytic modulators, and then the MTT assay was performed. For the membrane leakage assay, cyanobacteria were treated with BG-11 medium as a negative control, treated with $100 \%$ methanol as a positive control, or R9/GFP complexes in the presence of endocytic modulators. After a $24 \mathrm{~h}$ incubation, cells were washed with double-deionized water three times and then stained with $5 \mu \mathrm{M}$ of either SYTO 9 (LIVE/DEAD BacLight Bacterial Viability Kit, Molecular Probes, Eugene, OR, USA) or SYTOX blue (Invitrogen, Carlsbad, CA) [57] for $30 \mathrm{~min}$ at room temperature. SYTO 9 stains nucleic acids of live and dead prokaryotes in green fluorescence. SYTOX blue does not cross the membranes of live cells, whereas the nucleic acids of membrane-damaged cells fluoresce bright blue by SYTOX blue. After washing with double-deionized water, cells were observed using the TCS SP5 II confocal microscope system (Leica, Wetzlar, Germany).

\section{Fluorescent and confocal microscopy and autofluorescence observation}

Both bright-field and fluorescent images were observed using an Eclipse E600 fluorescent microscope (Nikon, Melville, NY, USA) and recorded using a Penguin 150CL cooled CCD camera (Pixera, Los Gatos, CA, USA), as previously described [58]. Confocal fluorescent images were obtained using both the TCS SL as previously described [24,59] and SP5 II confocal microscope systems (Leica). The parameters of the TCS SL confocal microscopy were set as follows: excitation at $488 \mathrm{~nm}$ and emission at 500-530 nm for the detection of GFP, and 
excitation at $543 \mathrm{~nm}$ and emission at 580-650 $\mathrm{nm}$ for the detection of red fluorescent protein (RFP). Intensities of fluorescent images were quantified using UN-SCAN -IT software (Silk Scientific, Orem, UT, USA). The parameters of the TCS SP5 II confocal microscopy were set as follows: excitation at $405 \mathrm{~nm}$ and emission at 436-480 $\mathrm{nm}$ for the detection of blue fluorescent protein (BFP), and excitation at $488 \mathrm{~nm}$ and emission at 498-523 $\mathrm{nm}$ for the detection of GFP.

For autofluorescence observation, cyanobacteria were treated with either BG-11 medium or $100 \%$ methanol for $24 \mathrm{~h}$. The cells were then washed with double deionized water three times followed by microscopic observation.

\section{Statistical analysis}

Results are expressed as mean \pm standard deviation (SD). Mean values and SDs were calculated from at least three independent experiments carried out in triplicates in each group. Statistical comparisons between the control and treated groups were performed by the Student's $t$-test, using levels of statistical significance of $P<0.05$ ${ }^{(*)}$ and $P<0.01\left(^{(* *)}\right)$, as indicated.

\section{Additional files}

Additional file 1: Figure S1. Endocytic inhibition in cyanobacteria. (A) Endocytic efficiency in cyanobacteria treated with NEM. Both 6803 and 7942 strains were treated with either $1 \mathrm{mM}$ or $2 \mathrm{mM}$ of NEM, followed by the treatment of GFP. (B) Endocytic efficiency in cyanobacteria treated with various endocytic modulators. Low temperature, $2 \mathrm{mM}$ of NEM, 10 $\mu \mathrm{M}$ of fusicoccin, $2 \mu \mathrm{M}$ of valinomycin, $2 \mu \mathrm{M}$ of nigericin, and $10 \mathrm{mM}$ of sodium azide were used as the physical and pharmacological inhibitors. Cells were treated with these inhibitors, followed by the treatment of GFP. Significant differences were set at $P<0.05\left(^{*}\right)$ and $P<0.01\left(^{* *}\right)$. Data are presented as mean \pm SD from three independent experiments.

Additional file 2: Figure S2. Cell viability analysis by the MTT assay. (A) Cell number determined by optical density (OD) at the wavelength of 600 $\mathrm{nm}$ linearly correlates with that assessed by the MTT assay at the wavelength of $570 \mathrm{~nm}$. (B) Physical or chemical treatments reduce cell viability. The 6803 strain of cyanobacteria was treated with 100\% methanol, 100\% DMSO, or autoclave, followed by the MTT assay. Physical or chemical treatment groups were compared with the group without any treatment. And chemical treatment groups were compared with the autoclave group. Significant differences were determined at $P<0.01\left(^{* *}\right)$. Data are presented as mean \pm SD from nine independent experiments.

\section{Abbreviations}

BFP: Blue fluorescent protein; CPP: Cell-penetrating peptide; CytD: Cytochalasin D; DMSO: Dimethyl sulfoxide; EIPA: 5-(N-ethyl-Nisopropyl)-amiloride; GFP: green fluorescent protein; MTT: 1-(4,5dimethylthiazol-2-yl)-3,5-diphenylformazan; NEM: N-ethylmaleimide; QD: Quantum dot; R9: Nona-arginine; RFP: Red fluorescent protein; Tat: Transactivator of transcription; SD: Standard deviation.

\section{Competing interests}

All authors declare no competing interests.

\section{Authors' contributions}

BRL performed all experiments and drafted the manuscript. YWH participated in the study design and helped drafting the manuscript. HJL conceived the study idea and assisted in drafting the manuscript. All authors read, commented, and approved the manuscript.

\section{Acknowledgements}

We thank Dr. Hsiu-An Chu (Academia Sinica, Taipei, Taiwan) for provision of cyanobacteria, Dr. Michael B. Elowitz (California Institute of technology, CA, USA) for the PQE8-GFP plasmid, and Core Instrument Center (National Health Research Institutes, Miaoli, Taiwan) for the TCS SP5 II confocal system. We are grateful to Dr. Robert S. Aronstam (Missouri University of Science and Technology, USA) for editing the manuscript. This work was supported by the Postdoctoral Fellowship NSC 101-2811-B-259-001 from the National Science Council of Taiwan (BRL), the Award Number R15EB009530 from the National Institutes of Health (YWH), and the Grant Number NSC 101-2320-B259-002-MY3 from the National Science Council of Taiwan (HJL).

\section{Author details}

'Department of Natural Resources and Environmental Studies, National Dong Hwa University, Hualien 97401, Taiwan. ²Department of Biological Sciences, Missouri University of Science and Technology, Rolla, MO 65409-1120, USA.

Received: 11 August 2012 Accepted: 8 March 2013

Published: 14 March 2013

\section{References}

1. Ruffing AM: Engineered cyanobacteria: teaching an old bug new tricks. Bioeng Bugs 2011, 2:136-149.

2. Herranen M, Battchikova N, Zhang P, Graf A, Sirpio S, Paakkarinen V, Aro EM: Towards functional proteomics of membrane protein complexes in Synechocystis sp. PCC 6803. Plant Physiol 2004, 134:470-481.

3. Huang F, Hedman E, Funk C, Kieselbach T, Schroder WP, Norling B: Isolation of outer membrane of Synechocystis sp. PCC 6803 and its proteomic characterization. Mol Cell Proteomics 2004, 3:586-595.

4. Shestakov SV, Khyen NT: Evidence for genetic transformation in bluegreen alga Anacystis nidulans. Mol Gen Genet 1970, 107:372-375.

5. Balasubramanian L, Subramanian G, Nazeer TT, Simpson HS, Rahuman ST, Raju P: Cyanobacteria cultivation in industrial wastewaters and biodiesel production from their biomass: a review. Biotechnol Appl Biochem 2011, 58:220-225.

6. Crosthwaite SK: Circadian timekeeping in Neurospora crassa and Synechococcus elongates. Essays Biochem 2011, 49:37-51.

7. Machado IMP, Atsumi S: Cyanobacterial biofuel production. J Biotechnol 2012, 162:50-56

8. Green M, Loewenstein PM: Autonomous functional domains of chemically synthesized human immunodeficiency virus Tat trans-activator protein. Cell 1988, 55:1179-1188.

9. Frankel $A D$, Pabo $C O$ : Cellular uptake of the Tat protein from human immunodeficiency virus. Cell 1988, 55:1189-1193.

10. Vives E, Brodin P, Lebleu B: A truncated HIV-1 Tat protein basic domain rapidly translocates through the plasma membrane and accumulates in the cell nucleus. J Biol Chem 1997, 272:16010-16017.

11. Wadia JS, Dowdy SF: Protein transduction technology. Curr Opinion Biotechnol 2002, 13:52-56.

12. Fonseca SB, Pereira MP, Kelley SO: Recent advances in the use of cellpenetrating peptides for medical and biological applications. Adv Drug Deliv Rev 2009, 61:953-964.

13. Tunnemann G, Ter-Avetisyan G, Martin RM, Stockl M, Herrmann A, Cardoso MC: Live-cell analysis of cell penetration ability and toxicity of oligoarginines. J Pept Sci 2008, 14:469-476.

14. Futaki S: Arginine-rich peptides: potential for intracellular delivery of macromolecules and the mystery of the translocation mechanisms. Int $J$ Pharm 2002, 245:1-7.

15. Lee CY, Li JF, Liou JS, Charng YC, Huang YW, Lee HJ: A gene delivery system for human cells mediated by both a cell-penetrating peptide and a piggyBac transposase. Biomaterials 2011, 32:6264-6276.

16. Dai YH, Liu BR, Chiang HJ, Lee HJ: Gene transport and expression by arginine-rich cell-penetrating peptides in Paramecium. Gene 2011, 489:89-97.

17. Chen YJ, Liu BR, Dai YH, Lee CY, Chan MH, Chen HH, Chiang HJ, Lee HJ: A gene delivery system for insect cells mediated by arginine-rich cellpenetrating peptides. Gene 2012, 493:201-210.

18. Liu BR, Lin MD, Chiang HJ, Lee HJ: Arginine-rich cell-penetrating peptides deliver gene into living human cells. Gene 2012, 505:37-45.

19. Liou JS, Liu BR, Martin AL, Huang YW, Chiang HJ, Lee HJ: Protein transduction in human cells is enhanced by cell-penetrating peptides fused with an endosomolytic HA2 sequence. Peptides 2012, 37:273-284. 
20. Liu MJ, Chou JC, Lee HJ: A gene delivery method mediated by three arginine-rich cell-penetrating peptides in plant cells. Adv Stud Biol 2013, 5:71-88

21. Liu BR, Chiang HJ, Huang YW, Chan MH, Chen HH, Lee HJ: Cellular internalization of quantum dots mediated by cell-penetrating peptides. Pharm Nanotechnol 2013, 1:151-161.

22. Hu JW, Liu BR, Wu CY, Lu SW, Lee HJ: Protein transport in human cells mediated by covalently and noncovalently conjugated arginine-rich intracellular delivery peptides. Peptides 2009, 30:1669-1678.

23. Li JF, Huang $Y$, Chen RL, Lee HJ: Induction of apoptosis by gene transfer of human TRAIL mediated by arginine-rich intracellular delivery peptides. Anticancer Res 2010, 30:2193-2202.

24. Lu SW, Hu JW, Liu BR, Lee CY, Li JF, Chou JC, Lee HJ: Arginine-rich intracellular delivery peptides synchronously deliver covalently and noncovalently linked proteins into plant cells. J Agric Food Chem 2010, 58:2288-2294

25. Gump JM, Dowdy SF: TAT transduction: the molecular mechanism and therapeutic prospects. Trends Mol Med 2007, 13:443-448.

26. Liu BR, Chou JC, Lee HJ: Cell membrane diversity in noncovalent protein transduction. J Membr Biol 2008, 222:1-15.

27. Liu BR, Huang YW, Chiang HJ, Lee HJ: Primary effectors in the mechanisms of transmembrane delivery of arginine-rich cell-penetrating peptides. Adv Stud Biol 2013, 5:11-25.

28. Madani F, Lindberg S, Langel U, Futaki S, Graslund A: Mechanisms of cellular uptake of cell-penetrating peptides. J Biophys 2011, 2011:414729.

29. Chang M, Chou JC, Chen CP, Liu BR, Lee HJ: Noncovalent protein transduction in plant cells by macropinocytosis. New Phytol 2007, 174:46-56.

30. Chen CP, Chou JC, Liu BR, Chang M, Lee HJ: Transfection and expression of plasmid DNA in plant cells by an arginine-rich intracellular delivery peptide without protoplast preparation. FEBS Lett 2007, 581:1891-1897.

31. Liu BR, Li JF, Lu SW, Lee HJ, Huang YW, Shannon KB, Aronstam RS: Cellular internalization of quantum dots noncovalently conjugated with arginine-rich cell-penetrating peptides. J Nanosci Nanotechnol 2010, 10:6534-6543.

32. Xu Y, Liu BR, Chiang HJ, Lee HJ, Shannon KS, Winiarz JG, Wang TC, Chiang $\mathrm{HJ}$, Huang YW: Nona-arginine facilitates delivery of quantum dots into cells via multiple pathways. J Biomed Biotechnol 2010, 2010:948543.

33. Liu BR, Huang YW, Winiarz JG, Chiang HJ, Lee HJ: Intracellular delivery of quantum dots mediated by a histidine- and arginine-rich HR9 cellpenetrating peptide through the direct membrane translocation mechanism. Biomaterials 2011, 32:3520-3537.

34. Hou YW, Chan MH, Hsu HR, Liu BR, Chen CP, Chen HH, Lee HJ: Transdermal delivery of proteins mediated by non-covalently associated arginine-rich intracellular delivery peptides. Exp Dermatol 2007, 16:999-1006.

35. Schulze K, Lopez DA, Tillich UM, Frohme M: A simple viability analysis for unicellular cyanobacteria using a new autofluorescence assay, automated microscopy, and ImageJ. BMC Biotechnol 2011, 11:118.

36. Tillich UM, Lehmann S, Schulze K, Duhring U, Frohme M: The optimal mutagen dosage to induce point-mutations in Synechocystis sp. PCC6803 and its application to promote temperature tolerance. PLoS One 2012, 7:e49467.

37. Hajek J, Vaczi P, Bartak M, Jahnova L: Interspecific differences in cryoresistance of lichen symbiotic algae of genus Trebouxia assessed by cell viability and chlorophyll fluorescence. Cryobiology 2012, 64:215-222.

38. Sato M, Murata $Y$, Mizusawa M: A simple and rapid dual-fluorescence viability assay for microalgae. Microbio/ Cult Collect 2004, 20:53-59.

39. Zeder M, Van den Wyngaert $\mathrm{S}$, Koster $\mathrm{O}$, Felder KM, Pernthaler J: Automated quantification and sizing of unbranched filamentous cyanobacteria by model-based object-oriented image analysis. Appl Environ Microbiol 2010, 76:1615-1622.

40. Kroth PG: Protein transport into secondary plastids and the evolution of primary and secondary plastids. Int Rev Cytol 2002, 221:191-255.

41. Karapetyan NV: Non-photochemical quenching of fluorescence in cyanobacteria. Biochemistry (Mosc) 2007, 72:1127-1135.

42. Chang M, Chou JC, Lee HJ: Cellular internalization of fluorescent proteins via arginine-rich intracellular delivery peptide in plant cells. Plant Cell Physiol 2005, 46:482-488.

43. Liu K, Lee HJ, Leong SS, Liu CL, Chou JC: A bacterial indole-3-acetyl-Laspartic acid hydrolase inhibits mung bean (Vigna radiata L.) seed germination through arginine-rich intracellular delivery. J Plant Growth Regul 2007, 26:278-284.
44. Ma DX, Shi NQ, Qi XR: Distinct transduction modes of arginine-rich cellpenetrating peptides for cargo delivery into tumor cells. Int J Pharm 2011, 419:200-208.

45. Koksharova OA, Wolk CP: Genetic tools for cyanobacteria. Appl Microbiol Biotechnol 2002, 58:123-137.

46. Ruffing AM, Jones HDT: Physiological effects of free fatty acid production in genetically engineered Synechococcus elongates PCC 7942. Biotechnol Bioeng 2012, 109:2190-2199.

47. Chang M, Hsu HY, Lee HJ: Dye-free protein molecular weight markers. Electrophoresis 2005, 26:3062-3068.

48. Nazarenko LV, Andreev IM, Lyukevich AA, Pisareva TV, Los DA: Calcium release from Synechocystis cells induced by depolarization of the plasma membrane: MscL as an outward $\mathrm{Ca}^{2+}$ channel. Microbiology 2003, 149:1147-1153.

49. Karnauchov I, Herrmann RG, Pakrasi HB, Klosgen RB: Transport of CtpA protein from the cyanobacterium Synechocystis 6803 across the thylakoid membrane in chloroplasts. Eur J Biochem 1997, 249:497-504.

50. Stamatakis K, Papageorgiou GC: The osmolality of the cell suspension regulates phycobilisome-to-photosystem I excitation transfers in cyanobacteria. Biochim Biophys Acta 2001, 1506:172-181.

51. Toyomasu T, Tsukahara M, Kaneko A, Niida R, Mitsuhashi W, Dairi T, Kato N, Sassa T: Fusicoccins are biosynthesized by an unusual chimera diterpene synthase in fungi. Proc Natl Acad Sci USA 2007, 104:3084-3088.

52. Liu BR, Huang YW, Chiang HJ, Lee HJ: Cell-penetrating peptidefunctionized quantum dots for intracellular delivery. J Nanosci Nanotechnol 2010, 10:7897-7905.

53. Nanbo A, Imai M, Watanabe S, Noda T, Takahashi K, Neumann G, Halfmann P. Kawaoka Y: Ebolavirus is internalized into host cells via macropinocytosis in a viral glycoprotein-dependent manner. PLOS Pathog 2010, 6:e1001121.

54. Hansen SH, Olsson A, Casanova JE: Wortmannin, an inhibitor of phosphoinositide 3-kinase, inhibits transcytosis in polarized epithelial cells. J Biol Chem 1995, 270:28425-28432.

55. Mellerick DM, Liu H: Methanol exposure interferes with morphological cell movements in the Drosophila embryo and causes increased apoptosis in the CNS. J Neurobiol 2004, 60:308-318.

56. Li J, Song L: Applicability of the MTT assay for measuring viability of cyanobacteria and algae, specifically for Microcystis aeruginosa (Chroococcales, Cyanobacteria). Phycologia 2007, 46:593-599.

57. Adav SS, Lin JC, Yang Z, Whiteley CG, Lee DJ, Peng XF, Zhang ZP: Stereological assessment of extracellular polymeric substances, exo-enzymes, and specific bacterial strains in bioaggregates using fluorescence experiments. Biotechnol Adv 2010, 28:255-280.

58. Wang YH, Chen CP, Chan MH, Chang M, Hou YW, Chen HH, Hsu HR, Liu K, Lee $\mathrm{HJ}$ : Arginine-rich intracellular delivery peptides noncovalently transport protein into living cells. Biochem Biophys Res Commun 2006, 346:758-767.

59. Wang $Y H$, Hou YW, Lee HJ: An intracellular delivery method for siRNA by an arginine-rich peptide. J Biochem Biophys Methods 2007, 70:579-586.

doi:10.1186/1471-2180-13-57

Cite this article as: Liu et al:: Mechanistic studies of intracellular delivery of proteins by cell-penetrating peptides in cyanobacteria. BMC Microbiology 2013 13:57.

\section{Submit your next manuscript to BioMed Central and take full advantage of:}

- Convenient online submission

- Thorough peer review

- No space constraints or color figure charges

- Immediate publication on acceptance

- Inclusion in PubMed, CAS, Scopus and Google Scholar

- Research which is freely available for redistribution 